\title{
SISTEMA DE INFORMAÇÕES GERENCIAIS NA GESTÃO DA ADMINISTRAÇÃO PÚBLICA
}

\section{ARTIGO ORIGINAL}

JUNIOR, Edelso Nepomuceno de Oliveira ${ }^{1}$

JUNIOR, Edelso Nepomuceno de Oliveira. Sistema de informações gerenciais na Gestão da Administração Pública. Revista Científica Multidisciplinar Núcleo do Conhecimento. Ano 04, Ed. 07, Vol. 10, pp. 05-19. Julho de 2019. ISSN: 2448-0959

\section{RESUMO}

O mundo vem ao longo dos anos passando por constantes mudanças advindas da globalização. Considerando o contexto atual, percebe-se que a circulação eficaz dentro das empresas para que decisões possam ser tomadas tem feito com que novas estratégias precisam ser tomadas para que essas organizações possam continuar a oferecer os seus produtos e serviços no mercado, e, dessa forma, sobreviver. Uma das estratégias que tem se revelado como eficaz para tal circulação são os conhecidos sistemas de informação. São ferramentas que possuem como escopo principal o auxílio aos gestores oferecendo como respaldo a tecnologia para a otimização das suas atividades. Esses sistemas são responsáveis por agilizar e otimizar as funções diárias a serem cumpridas pelas empresas para que essas permaneçam no mercado. Agem, principalmente, no processo de tomada de decisão. É uma estratégia eficaz porque responde, positivamente, as mais diversas transformações que tomam forma no mundo a cada novo dia. O seu diferencial se concentra no fato de que propõe novas óticas para os gestores a partir do oferecimento de fontes tecnológicas, ágeis e seguras. Nesse contexto, observa-se que esses sistemas direcionados à gerência dessas empresas, quando usados corretamente, fazem com que essas informações recebidas sirvam de auxílio para que decisões sábias e condizentes com o contexto atual da sociedade sejam tomadas, sobretudo porque fornecem dados ágeis e

\footnotetext{
${ }^{1}$ Pós-Graduado em Gestão Pública e Bacharel em Administração.
} 
temporais, o que é um ponto positivo para se destacar no mercado competitivo. Assim, o objetivo deste trabalho fundamenta-se em elaborar um conjunto de informações, colhidas em livros, artigos, sites, jornais, revistas que possam contribuir na construção do tema desse artigo, que é sobre Sistema de informações gerenciais na Gestão de Administração Pública. A temática foi adotada a partir da necessidade de incorporar os conceitos, métodos e estratégias teóricas aprendidos durante o curso em um trabalho final. A metodologia utilizada é do tipo descritiva, ou seja, uma pesquisa aplicada, considerando, para tanto, uma revisão de literatura pautada em materiais diversos para o embasamento teórico deste artigo.

Palavra-chave: Administração, informações, pública, gerenciais, sistema.

\section{INTRODUÇÃO}

O mundo vem ao longo dos anos passando por constantes mudanças advindas da globalização. A informação atualmente é papel fundamental para o desenvolvimento de qualquer organização e para a tomada de decisões, até mesmo para a sustentação da empresa no mercado, logo entende-se, ser uma questão de sobrevivência. Os sistemas de informação são mecanismos de apoio à gestão, desenvolvidos com base na tecnologia da informação tendo como amparo, sobretudo, os conceitos e teorias informáticos. Apoiam-se neles para, principalmente, transmitir essas informações de forma ágil para facilitar e otimizar o desempenho das tarefas diárias executadas por uma empresa bem como para que os gestores tomem as decisões tendo como respaldo esses sistemas de informação.

Sendo assim, em função de constantes mudanças, em qualquer que seja o cenário, principalmente no que diz respeito a ascensão tecnológica, um bom sistema de informação é um fator fundamental na tomada de decisão ágil, segura. Os gestores enfrentam grandes desafios no cenário competitivo mundial, demandando informações que espelhem as necessidades organizacionais na obtenção dos resultados esperados. $O$ desenvolvimento dos sistemas de informações gerenciais faz com que as empresas esperem, principalmente, pela segurança e veracidade das 
informações, visto que consideram o conteúdo transmitido por esses sistemas para tomarem decisões que podem, inclusive, definir o futuro dessas empresas.

A correta utilização dos seus dados é essencial para as instituições possam continuar a ofertar os seus produtos e serviços de forma condizente com o que a sociedade espera. Nesse sentido, os dados precisam chegar de forma contínua, sendo a sua atualização indispensável para que decisões sábias possam ser tomadas. O objetivo deste trabalho fundamenta-se em elaborar um conjunto de informações, colhidas em livros, artigos, sites, jornais, revistas que possam contribuir na construção do tema desse artigo, que é sobre Sistema de informações gerenciais na Gestão de Administração Pública. Este tema foi escolhido com a finalidade aliar o conhecimento teórico, e a atender as especificações exigidas por um Trabalho de Conclusão de Curso. A metodologia utilizada é do tipo descritiva, uma pesquisa aplicada, sobre uma revisão de literatura em livros de autores renomados, que possam contribuir para o desenvolvimento desse artigo científico.

\section{SISTEMA DE INFORMAÇÃO}

Conforme O'Brien (2006), os denominados sistemas de informação sobre os quais essa pesquisa se propõe refletir, tratam-se de conjuntos elaborados por especialistas a partir de suportes de hardware ou software a serem utilizados por empresas. Dessa forma, pesquisas defendem que podem ser entendidos como uma rede de comunicação que recruta dados e recursos para, posteriormente, convertê-los em informações a serem acionadas pelos gestores em seus processos de tomada de decisão. A partir dessa transformação dos dados em informações, essas podem começar a ser disseminadas pela empresa, sobretudo para que a partir dessas novas informações, novas estratégias, produtos e ferramentas sejam aderidos/executados. Nesse contexto, a relevância social dos sistemas de informação consiste no fato de que é um mecanismo

Essencial para os administradores, porque a maioria das organizações precisa deles para sobreviver e prosperar. Com os sistemas, as empresas podem aumentar o seu grau e alcance de participação no 
mercado, oferecer novos produtos, adequar-se internamente e, muitas vezes, transformar radicalmente o modo como conduzem seus negócios (LAUDON; LAUDON, 2007, p. 23).

É preciso reiterar que os sistemas de informação devem possuir como escopo principal, também, a oferta de feedbacks constantes. Esses, todavia, devem ser entendidos como dados relacionados ao desempenho do sistema utilizado pela empresa para ter acesso às informações. Esse feedback, por sua vez, tem como missão desempenhar atividades ligadas ao monitoramento e avaliação das informações que chegam até esses gestores, garantindo, sobretudo, a sua qualidade e veracidade, de forma a auxiliar no cumprimento de metas estabelecidas pela empresa. Nesse sentido, deve-se distinguir dado de informação. Assim:

Qualquer elemento identificado em sua forma bruta que por si só não conduz a uma compreensão de determinado fato ou situação. Informação é o dado trabalhado que permite ao executivo tomar decisões. Também, informação é o produto da análise dos dados existentes na empresa, devidamente registrados, classificados, organizados, relacionados e interpretados dentro de um contexto para transmitir conhecimento e permitir a tomada de decisão de forma otimizada (OLIVEIRA, 2010, p. 110).

De acordo com Resende (2009), a informação deve ser entendida como processo de trabalho com os dados obtidos. Desempenha, nesse sentido, um processo de tratamento desses dados, auferindo-Ihes um valor significativo ou agregado a esse dado, fazendo com que ele, de forma natural e lógica, transforme-se em uma informação. Assim, o dado pode ser compreendido como um elemento indispensável que atribui forma à informação. Dessa forma, em sua composição, apresenta letras, números ou dígitos até que seja transformado em informação. Sem esse tratamento dos dados, os números, letras ou dígitos não possuirão nenhum significado, logo não serão capazes de transmitir novos conteúdos aos gestores. 
Segundo Laudon e Laudon (2007), a partir de uma perspectiva técnica, um sistema de informação pode ser compreendido como um conjunto que se configura a partir de elementos interligados. Dessa forma, realizam, de forma contínua, a coleta, recuperação, processamento, armazenamento e distribuição das informações, de forma a apoiar os gestores no processo de tomada de decisão, dispondo de informações coordenadas e controladas. São responsáveis, também, por fazer com que os gestores sejam capazes de analisar diversas situações, abordar novos assuntos bem como auxiliam no processo de criação de novos produtos, sobretudo porque esses possuem informações sobre pessoas, locais e outros elementos aos quais uma organização responde por meio da oferta de produtos e serviços.

Informação quer dizer dados apresentados em uma forma significativa e útil para os seres humanos. Dados, ao contrário, são correntes de fatos brutos que representam eventos que estão ocorrendo nas organizações ou no ambiente físico, antes de terem sido organizados e arranjados de uma forma que as pessoas possam entende-los e usá-los (LAUDON; LAUDON, 2007, p. 132).

Segundo Stair e Reynolds (2012) os sistemas de informação devem apoiar, de forma direta, a gestão das empresas, fornecendo, para tanto, tecnologia da informação tendo como suporte a informática, por exemplo, que, por sua vez, deve atuar como uma mediadora dessas informações, de forma a facilitar, agilizar e otimizar a prática diária dos gestores no ambiente laboral. Assim, podem ser compreendidos como recursos de caráter humano, material, tecnológico e financeiro agregados a uma sequência lógica voltada ao processamento de dados. Atua, dessa forma, como uma espécie de tradutor dos dados convertidos em informações. Todavia, uma outra perspectiva entende que esses sistemas têm como objetivo central atuar, unicamente, no plano empresarial, pois, caso contrário, estariam direcionados à negócios secundários ou de apoio.

Grande volume de dados e informações; Complexidade de pensamentos; muitos clientes e/ou usuários envolvidos; Contexto abrangente, mutável e dinâmico; Interligação de diversas técnicas e 
tecnologias; Suporte à tomada de decisões empresariais; Auxílio na qualidade, produtividade e competitividade organizacional (REZENDE, 2009, p. 41).

\section{CLASSIFICAÇÃO DE SISTEMAS DE INFORMAÇÃO}

Para Turban (2010), é possível realizar a classificação dos denominados sistemas de informação considerando, principalmente, a natureza das atividades aos quais estão ligados. Dentre as modalidades existentes as principais são os Sistemas de Informação Operacional; os Sistemas de Informação Gerencial; os Sistemas de Informação Estratégico; os Sistemas Especialistas e os Sistemas de Apoio à Decisão. Renata Resende (2009, p. 54), em seu estudo, defende que os sistemas de caráter operacional podem, também, aparecer com os títulos de Sistemas de Apoio as Operações Empresariais, Sistemas de Controle ou Sistemas de Processamento de Transações. Dentre as suas principais funções costumam desempenhar operações ou transações de caráter cotidiano para executar os seus procedimentos. Nessa perspectiva, cada transação empresarial envolve aspectos como:

A entrada e a alimentação de dados, 0 processamento e 0 armazenamento, e a geração de documentos e relatórios. Com suas inúmeras características, como grande volume de dados, muitas saídas de informações, envolvendo alto grau de repetição e computação simples. As edições, validações, consistências e auditorias são comuns nesses sistemas, devido ao envolvimento de inúmeras pessoas e respectivas coletas de dados e alimentações nos mesmos, significando impactos grandes e negativos se houver falhas de operação, cálculos, seleções, ordenações, conciliações e reprocessamentos, com bases de dados diversas.

Outra corrente teórica compreende que o Sistema de Informações Gerenciais deve ser compreendido como o processo de conversão dos dados sem sentido em informações com valores agregados e que, assim, podem ser utilizadas para que os gestores tomem as melhores decisões para a empresa. São eficazes, também, em 
processos que envolvem aspectos como a administração e otimização dos resultados esperados. Nesse sentido, ainda sobre esse tipo de sistema, pode-se afirmar que ele é:

Um método organizado de prover informações passadas, presentes e futuras, relacionadas com as operações internas e o serviço de inteligência externa. Serve de suporte para as funções de planejamento, controle e operação de uma empresa através do fornecimento de informações no padrão de tempo apropriado para assistir o tomador de decisão (OLIVEIRA, 2010, p. 39).

Os sistemas de informação de caráter estratégico, por sua vez, são responsáveis por fornece o suporte necessário para que novas estratégias possam ser propostas para que a empresa consiga competir no mercado a partir da elaboração do que se denominou de unidade de negócios. Dessa forma, esse tipo de sistema tem como característica inerente e indissociável:

A capacidade de modificar significativamente a maneira de conduzir um negócio. Pode também modificar os objetivos, processos, produtos e relações ambientais para ajudar uma organização a ganhar vantagem competitiva. Um sistema de informação estratégico ajuda a organização a obter vantagem competitiva mediante sua contribuição para a concretização dos objetivos estratégicos da organização e ou por sua capacidade de melhorar significativamente o desempenho e a produtividade (TURBAN, 2010, p. 290).

Diz Batista (2006, p. 118) que os sistemas especialistas devem ser encarados como uma ferramenta ligada à esfera da inteligência artificial. Devido à tal ligação, esse sistema é capaz de, a partir do computador, assistir a execução de decisões ou até mesmo podem substituir esses tomadores de decisões, que, geralmente, são os gestores das empresas. Compõem-se de softwares que pretendem adquirir conhecimentos de certas áreas para obter mais conhecimento e dados sobre comportamentos humanos para, a partir dessa coleta, elaborar novas estratégias de 
aplicação dessas informações para a resolução de problemas. De acordo com Stair (2012, p. 342), os sistemas especialistas são desenvolvidos para diagnosticar problemas, prever eventos futuros e resolver problemas de energia. Também são:

Empregados para projetar novos produtos e sistemas, determinar o melhor uso para sobras de madeira, estabelecer limites de créditos e aumentar a qualidade dos serviços médicos. Podem explorar novas oportunidades de negócio, aumentar a lucratividade geral, reduzir custos e fornecer serviços de maior qualidade aos clientes e consumidores.

Por fim, o Sistema de Apoio à Decisão pode ser definido como um sistema que a partir de um computador, realiza a combinação de modelos e dados para solucionar problemas de forma semiestruturada. Em detrimento de tal peculiaridade, há um envolvimento expressivo do usuário neste processo. Ainda sobre esses sistemas, deve-se frisar que:

Os sistemas que possuem interatividade com as ações do usuário, oferecendo dados e modelos para a solução de problemas semiestruturados e focando a tomada de decisões. Constituindo o principal exemplo de tomadas de decisão auxiliadas pelo computador, esses sistemas devem possuir grande interação com os profissionais táticos da empresa, além de uma fácil flexibilidade, adaptabilidade e capacidade de resposta rápida (BATISTA, 2006, p. 170).

\section{O SURGIMENTO DA ADMINISTRAÇÃO}

Maximiano (2010, p. 155), esclarece que a área administrativa teve o seu ensejo como um conjunto limitado de conhecimentos colocados em prática na Europa do século XVIII, em meados da Revolução Industrial. Neste período, havia certa tendência a colocar esses conceitos em prática na esfera laboral, sobretudo para pensar o trabalho desempenhado nas indústrias modernas. Dessa forma, este período histórico foi um marco expressivo para a consolidação da área da administração. Contudo: 
Vários autores afirmam que a administração já existe desde a Antiguidade. E a partir do início do século XX, a organização eficiente do trabalho nas empresas tornou-se a base no desenvolvimento da teoria e da prática da administração.

Para Milkovich e Boudreau (2008), o domínio da Administração não possui uma base concreta acerca do seu surgimento bem como em relação ao seu desenvolvimento, ou seja, não há um consenso sobre esses dois fenômenos, sobretudo na Antiguidade. Todavia, especula-se que com a construção das pirâmides, e, consequentemente, da estrutura das cidades, sobretudo de Atenas, a administração passou a ser necessária, como no Império Romano, por exemplo.

Gobe (2009), em seu estudo, defende que, desde a gênese da humanidade, o ser humano tende a estabelecer metas para cumprir determinados objetivos e planos. Essas práticas modificaram, radicalmente, a estrutura social e comercial durante a Revolução Industrial, provocando, dessa forma, severas mudanças. Este período teve início, aproximadamente, no ano de 1776. Era comum a presença da máquina a vapor para o aceleramento dos processos de produção. São artefatos históricos que influenciam, até hoje, a prática diária das empresas.

De acordo com Chiavenato (2010), tal período histórico ganhou as suas características em duas épocas: a primeira delas correspondeu ao período de 1760 até 1780 (fase em que o carvão era utilizado como a principal matéria de energia e o ferro como a matéria-prima mais desejada, logo, principal) e a segunda durou de 1860 a 1914 (evolução da eletricidade e dos derivados do petróleo). Para o autor, dentro da Revolução Industrial, teve-se uma outra vertente, marcada por alguns acontecimentos tais como:

Desenvolvimento de novos processos de fabricação de aço (1856); aperfeiçoamento do dínamo (1873); invenção do motor de combustão interna (1873); desenvolvimento da maquinaria automática e especialização do trabalho; domínio da indústria pela ciência; transformação nos transportes e nas comunicações; desenvolvimento 
de novas organizações capitalistas e, a expansão da industrialização (CHIAVENATO, 2010, p. 87).

Segundo Chiavenato (2010), o principal desafio da esfera administrativa é a realização das tarefas a partir das pessoas com os conhecimentos necessários, de forma eficiente e eficaz, em todos os lugares que precisam ser administrados: desde as indústrias e comércios até as organizações públicas e privadas, hospitais, universidades e afins. Sobre a origem do termo, estudos apontam que ele é advindo do latim, assim, a locução ad significa uma direção ou uma tendência para alguma coisa e minister, por sua vez, significa ser subordinado ou ser ordenado por alguém que exerce uma função superior, ou seja, é aquele que presta serviços a outrem superior.

Para Ribeiro (2006), a Administração pode, ainda, ser entendida como a arte de realizar coisas por intermédio das pessoas a partir de grupos previamente organizados. Para tanto, deve-se aplicar técnicas derivadas do conhecimento teórico de caráter administrativo que pode ter como base as esferas da Psicologia, da Sociologia, da Economia, da Matemática bem como de outras áreas correlacionadas. Esse conhecimento acumulado deve ser voltado para a utilização de métodos e conceitos sobretudo quando é preciso tomar decisões de forma estratégica nas organizações.

Na visão de Maximiano (2010), por fim, o domínio administrativo é defendido como um conjunto composto de princípios, normas e funções que tem como escopo principal a ordenação da produção de uma empresa, por exemplo, de forma a controlar a sua produtividade e eficiência para se obter resultados, principalmente, positivos. Assim, a Administração pode ser concebida como uma área voltada ao auxílio nos processos de tomadas de decisões e realização de ações a partir de quatro fases: planejamento, organização, execução e controle. 


\section{PRINCÍPIOS BÁSICOS DA ADMINISTRAÇÃO PÚBLICA}

Demonstrou Bacellar Filho (2009) que os princípios básicos da Administração Pública devem estar presentes como regra e alicerce de suas atividades. Se desvirtuados, farão desaparecer por ilegítimas, a natureza e a finalidade da Administração Pública e de seus agentes. Os conflitos entre regras são resolvidos com base na exclusão, na opção por uma e exclusão de outra, já os princípios podem coexistir, aplicando-se um ou mais ao caso concreto.

Como norma, têm peculiaridades quando comparadas com as regras, por exemplo em caso de conflito de princípios, ao qual se aplica a ponderação de valores, onde um pode se sobressair a outro sem, contudo, invalidá-lo. (BACELLAR FILHO, 2009). Segundo Melo (2014, p. 324) princípio da Supremacia do Interesse Público sobre o Interesse Privado:

A principal consequência deste princípio é o fato da Administração ocupar posição privilegiada sobre os particulares, por estar realizando o bem comum, assim sendo, justifica-se certas prerrogativas do Estado, que se consubstanciam-se na auto executoriedade, auto tutela, poder de expropriar, poder de requisitar bens e serviços, poder de ocupar imóvel alheio, de instituir servidão, aplicar sanções administrativas, alterar e até rescindir contratos unilateralmente, impor medidas de polícia, gozar de imunidade tributária, prazos dilatados em juízo, juízo privativo, processo especial de execução, presunção de veracidade de seus atos.

De acordo com Melo (2014, p. 325), o princípio da legalidade no Brasil, demonstrou que:

A Administração nada pode fazer senão o que a lei determina. Ao contrário dos particulares, os quais podem fazer tudo o que a lei não proíbe, a Administração só pode fazer o que a lei antecipadamente autorize. Integra o princípio da legalidade o princípio da finalidade e da motivação. 
Segundo Melo (2014), deve-se enfatizar a diferença entre o denominado Princípio da Supremacia do Interesse Público e o Princípio da Legalidade para que sejam evitadas possíveis confusões quanto aos seus usos. Enquanto o primeiro é pertinente e indispensável à essência de qualquer Estado, logo, de qualquer sociedade que esteja, juridicamente, organizada a partir de fins de caráter político, o segundo, por sua vez, é posse exclusiva do Estado de Direito, assim, é ele que constrói a identidade desta legalidade, auferindo-Ihe qualificações.

Conforme Figueiredo (2008), o Princípio da Impessoalidade carrega, em sua essência, o objetivo de que todos os administrados sejam tratados da mesma forma, logo, discriminações, sejam elas benéficas ou maléficas, devem ser evitadas, assim, qualquer forma de favoritismo ou perseguição é passível à punição bem como simpatias e animosidades de caráter político e/ou ideológico não podem interferir, de forma direta ou indireta, no exercício administrativo. Dessa forma, pode ser entendido como o princípio da igualdade ou isonomia.

De acordo com Figueiredo (2008, p. 178), o princípio da moralidade administrativa mostra que a Administração deve seguir dentro do limite da moralidade. Não a moral comum a todas as pessoas, mas a uma moralidade que seja própria da Administração Pública. Alguns juristas interpretam tal princípio como:

Um atendimento ao princípio da legalidade, ou seja, o que for legal é moral, o que não for legal não é moral, mas não é isto que indica o princípio, mesmo porque se assim fosse bastaria apenas enumerar o princípio da legalidade na Constituição. Podem haver leis que sejam imorais, de modo que a atuação do administrador fosse conforme a lei, mas não conforma a moralidade administrativa.

Princípio da Publicidade, de acordo com Freitas (2015, p. 219):

Visa dar transparência à Administração e a seus atos. Na esfera administrativa o sigilo só se admite quando imprescindível à segurança da Sociedade e do Estado. Assim, a atividade administrativa é exercida 
às claras, possibilitando seu acompanhamento por qualquer cidadão. Quanto ao controle da administração, o princípio da publicidade importa pelo fato de que os atos da administração podem ser analisados não apenas pelos órgãos do Legislativo e do Judiciário, mas também do cidadão possibilitando o exercício do controle social.

Para Di Pietro (2014), o Princípio da Eficiência se configura a partir de dois aspectos fundamentais: é voltado, em uma primeira vertente, ao modo de atuação do agente público, esperando-se, dessa forma, o melhor desempenho possível das suas funções para que resultados positivos tomem forma e, em uma segunda vertente, deve organizar, estruturar e disciplinar a esfera da Administração Pública visando, sobretudo, o alcance de melhores resultados ao prestar serviços públicos aos cidadãos.

Ensinou Melo (2014, p. 328), Princípio da Razoabilidade e da Proporcionalidade:

Estes princípios a Administração ao atuar, no exercício de discrição, terão de obedecer a critérios aceitáveis do ponto de vista racional, em sintonia com o senso normal de pessoas equilibradas e respeitosa das finalidades que presidiram a outorga da competência exercida.

Especificamente sobre o Princípio da Razoabilidade, Di Pietro (2014) elucida que embora estejam sujeitos aos limites da discricionariedade do legislador ou ainda do administrador público, é defendido como um conceito, em muitas das vezes, indeterminado, visto que não existem critérios objetivos que tornem possível a diferenciação do que é, por exemplo, uma lei ou um ato administrativo razoável proposto por uma lei ou ato irrazoável.

Integra o princípio da razoabilidade o princípio da proporcionalidade, segundo o qual as competências administrativas só podem ser validamente exercidas na extensão e intensidade proporcionais ao que seja realmente demandado para cumprimento da finalidade de interesse público a que estão atreladas. (MELO, 2014)

Oliveira (2009, p. 203), afirmou que: 
A irrazoabilidade, e, a desproporcionalidade são vícios de extrema gravidade, seja sob a forma de falta de ponderação, seja de desproporção de ponderação, a ponderação ganha estrutura pelo princípio da proporcionalidade, sob a égide de seus três escalões normativos. Ao Poder Judiciário, no exercício de sua missão constitucional, incumbe realizar o controle judicial fundamentado na aplicação dos princípios da razoabilidade e da proporcionalidade, como garantia da tutela judicial efetiva consagrada na Constituição em favor dos administrados.

O que o princípio da proporcionalidade, segundo Gabardo (2010), é a adequação entre os meios e os fins dos atos administrativos. O meio deve ser o suficiente para se realizar o fim, qualquer excesso cai na esfera da ilegalidade do ator, ferindo-se assim o princípio da razoabilidade.

\section{GESTÃO PÚBLICA}

Para Chiavenato (2010), o gestor público não deve temer a perda do poder político, deve entende-la como uma aliada, assim, é preciso conhecer e saber utilizar de forma inteligente tal poder, de forma a conquistar um maio prestígio político. É apenas agindo dessa forma que o gestor conseguirá gerir, de forma administrativa e política, pessoas ou organizações de maneira objetiva, racional e eficiente.

Entretanto, Carmem e Zanini (2015), defendem que a gestão pública deve considerar, sobretudo, o Princípio Econômico da Escassez, entendendo, dessa forma, que as demandas sociais não possuem um fim, mas que os recursos financeiros possuem, assim, devem ser bem administrados para que estejam em consonância com tais demandas. Torna-se fundamental que haja uma administração eficaz e eficiente desses recursos para que os interesses coletivos sejam atendidos.

De acordo com Pereira (2008) o gestor público é o agente mais indispensável para os processos que envolvem o planejamento, o assessoramento deliberativo, a coordenação de ações assim como para a avaliação de programas e políticas públicas 
de organizações estatais e não estatais, sejam elas nacionais ou estrangeiras. Nesse contexto, a sua atuação diária compreende as mais diversas esferas: a União, os estados e os municípios, visto que todos eles fazem uso de recursos voltados a produção de bens de caráter público.

Nessa perspectiva, a gestão pública para o administrador público é uma ferramenta essencial, pois auxilia nos mais diversos processos diários executados por esses agentes bem como porque a gestão delimita, de maneira objetiva, as esferas em que atua assim como indica os passos para que os serviços/bens públicos sejam bem administrados. A gestão do administrador público, por sua vez, compreende três esferas:

Atos de governo, que se situam na órbita política; atos de administração, atividade neutra, vinculada à lei; atos de gestão, que compreendem os seguintes parâmetros básicos: I- tradução da missão; II- realização de planejamento e controle; III- administração de R. H., materiais, tecnológicos e financeiros; IV- inserção de cada unidade organizacional no foco da organização; e V- tomada de decisão diante de conflitos internos e externos (SANTOS, 2006, p. 123).

Todavia, Pacheco (2017), defende que a Gestão Pública, de forma contínua, deve propor estratégias inovadoras para que o administrador possa usar em sua atuação diária, propondo, para tanto, técnicas advindas do setor privado, contudo, adaptadas para atuação no setor público. É sua responsabilidade, ainda, desenvolver novas ferramentas para a manutenção da eficácia e eficiência econômica e social. Sua missão principal é o oferecimento de oportunidades destinadas à melhoria das condições econômicas, sociais e culturais do cidadão.

Nesse contexto, para que essa inovação seja colocada em voga, a gestão deve ter como subsídio a informação, pois esse conteúdo absorvido pelos gestores deve ser capaz de fazê-los tomar decisões apropriadas depois de um processo de análise a armazenamento dessas informações. Essas devem, ainda, atuar como uma fonte 
efetiva para que decisões futuras possam ser tomadas, devendo, para tanto, ser submetidas a um novo controle e avaliação posteriormente (CARMEN; ZANINI, 2015).

Por fim, para Oliveira (2012), a gestão pública pode ser compreendida como uma ferramenta que carrega, em sua essência, valores éticos, morais e legais advindos do contato daqueles que a movimentam em sua atuação diária, principalmente na figura dos administradores públicos. Tem-se como escopo principal a obtenção de resultados positivos a partir de uma gestão eficiente dos bens e recursos públicos. Devido ao contexto moderno, as informações que dão forma à gestão pública devem ser carregadas de tecnologia e inovação, visto que o mercado atual pede por essa demanda, sobretudo porque tais recursos facilitam o processo de gestão para se administrar tais bens e serviços públicos.

\section{CONCLUSÃO}

Na sociedade contemporânea o mercado tem se revelado, cada vez mais, como competitivo. Assim, decisões precisam ser tomadas em consonância com essa competitividade, dessa forma, precisam ser rápidas e eficientes para que os gestores das empresas ganhem uma certa vantagem frente aos seus concorrentes. Considerando tal contexto, as organizações têm buscado pelos sistemas de informação para lidar com as demandas desse mercado, visto que eles aumentam a eficácia da gestão das empresas. Com este estudo foi possível perceber, também, que a gestão de pessoas passa, de forma contínua, por modificações.

Uma das causas para este fenômeno é a globalização da informação, responsável por fazer com que a concorrência tome grandes proporções no mercado, impulsionando, dessa forma, os gestores a buscar por funcionários qualificados. Nesse contexto, os sistemas de informação atuam como ferramentas em potencial, pois fomentam uma gestão mais eficiente e engajada com as demandas sociais. Dessa forma, torna-se necessário aderir às novas tecnologias da informação bem como deve-se contar com o apoio da informática para lidar com a urgência da sanção das mais diversas necessidades apontadas pelo mercado que representa a sociedade e as suas demandas. 
Assim, o uso dos sistemas de informação facilita, agiliza e otimiza a conversão das informações em novos produtos e serviços a serem ofertados ao mercado. Percebese que com o advento da tecnologia da informação, adesão aos Sistemas de Informações Gerenciais tem se revelado como uma estratégia positiva para que as empresas consigam se manter no mercado competitivo. Assim, é preciso, a partir desses sistemas, tomar as decisões de forma mais rápida para que a estratégia seja eficiente e a gestão significativa.

Os gestores adotam instrumentos que permitem maior flexibilidade, velocidade, inovação e integração para atuar num ambiente formado por constantes mudanças. Assim, a ação de tomar decisões, em uma corporação é uma responsabilidade que precisa ser muito bem planejada. Para garantir a qualidade das informações geradas, as equipes devem trabalhar integradas, de forma que qualquer mudança tenha seu impacto analisado.

\section{REFERÊNCIAS}

BACELLAR FILHO, R. F. Direito Administrativo. São Paulo: Saraiva, 2009.

BATISTA, E. Sistemas de Informação: o uso consciente da tecnologia para o gerenciamento. São Paulo: Saraiva, 2006.

CARMEM, M.; ZANINI, M. T. Excelência em Gestão Pública: Espaços para Atuação. Rio de Janeiro: Atlas, 2015.

CHIAVENATO, I. Gestão de Pessoas: o novo papel dos recursos humanos nas organizações. Rio de Janeiro: Elsevier, 2010.

CHIAVENATO, I. Iniciação a Administração de Recursos Humanos. São Paulo: Manole, 2010.

DE OLIVEIRA, R. Gestão pública: Democracia e eficiência. Rio de Janeiro: FGV, 2012. 
DI PIETRO, M. S. Z. Direito Administrativo. 27. ed. São Paulo: Atlas, 2014.

FIGUEIREDO, L. V. Curso de direito administrativo. 9. ed. Rev., atual. e ampl. São Paulo: Malheiros, 2008.

FREITAS, J. O controle dos atos administrativos e os princípios fundamentais. 5. ed. rev. e ampl. São Paulo: Malheiros, 2015.

GABARDO, E. Princípio constitucional da eficiência administrativa. São Paulo: Dialética, 2010.

GOBE, A. C. et al. Administração de vendas. São Paulo: Saraiva, 2009.

LAUDON, K. C.; LAUDON J. P. Sistemas de informação gerenciais: administrando a empresa digital. 7. ed. São Paulo: Prentice Hall, 2007.

MAXIMIANO, A. C. A. Introdução à Administração. 7. ed. São Paulo: Atlas, 2010.

MELO, C. A. B. Curso de direito administrativo. 31. ed. São Paulo: Malheiros, 2014.

MILKOVICH, G. T.; BOUDREAU, J. W. Administração de Recursos Humanos. São Paulo: Atlas, 2008.

O’BRIEN, J. A. Sistemas de informações e as decisões gerencias na era da Internet. 9. ed. São Paulo: Saraiva, 2006.

OLIVEIRA, J. R. P. Os princípios da razoabilidade e da proporcionalidade no direito administrativo brasileiro. São Paulo: Atlas, 2009.

OLIVEIRA, D de P. R. de. Sistemas de Informações Gerenciais: Estratégicas, Táticas e Operacionais. 13. ed. São Paulo: Atlas, 2010.

PACHECO, R. S. Reformando a Administração Pública No Brasil: Eficiência e Accountability Democrática. Disponível em: <http://www.fundaj. gov.br/docs/eg/semi4.rtf> Acesso em: 30 de abril de 2017. 
PEREIRA, J. M. Manual de Gestão Pública Contemporânea. São Paulo, Atlas, 2008.

REZENDE, D. A; ABREU, A. F. de. Tecnologia da Informação aplicada a sistemas de Informação Empresariais. 6. ed. São Paulo: Atlas, 2009.

RIBEIRO, A. de. L. Gestão de pessoas. São Paulo: Saraiva, 2006.

SANTOS, C. S. dos. Introdução à Gestão Pública. São Paulo: Saraiva, 2006.

STAIR, R. M.; REYNOLDS. Princípios de sistemas de Informação. 8. ed. Rio de Janeiro: LTC, 2012.

TURBAN, E. et al. Tecnologia da informação para gestão. Porto Alegre: Bookman, 2010.

Enviado: Janeiro, 2019.

Aprovado: Julho, 2019. 